\title{
OR and Strategy: Editorial Introduction
}

This edition of JORS includes a selection of articles at the intersection of operational research and strategy. The articles have been edited by myself and Colin Eden, and a second batch will appear in the July edition.

In the first article (my Presidential Address to the Society), it is argued that OR is well fitted to contribute at the strategic level in organisations. This contribution is categorised into strategic OR (using models to provide sustainable competitive advantage), strategy support, and public policy analysis. The article focuses on strategy support and argues that OR has an opportunity to raise its profile and set agendas in the strategic arena.

The article by Colin Eden and Fran Ackerman continues their tradition of work in furthering the contribution of models and group support systems in developing strategic direction, in this instance by mapping distinctive competencies. This is complemented by the article by Peter Grinyer which describes a cognitive approach to group strategic decision making in the face of complexity and uncertainty.

The articles by John Foster, and Frances O'Brien and Maureen Meadows continue the strategy support theme. The former addresses the problem for firms of evaluating foreign direct investment, whilst the latter surveys the way corporations develop visions. The final article by Brian Dangerfield and Carole Roberts describes the use of system dynamics modelling to understand the unintended consequences of the strategy adopted in the UK steel industry.

This set of articles, and those to follow, are in support of the policy of the Journal editor, John Ranyard, to broaden the appeal of JORS, making it fit better with the changing nature of $\mathrm{OR}$, whilst retaining and enhancing its position as a leading international journal.

Robert Dyson University of Warwick 